\title{
Cognitive development of term small for gestational age children at five years of age
} K Sommerfelt, H W Andersson, K Sonnander, G Ahlsten, B Ellertsen, T Markestad,
G Jacobsen, H J Hoffman, L Bakketeig term SGA children most likely have a mean IQ that is $5-10$ points lower than AGA controls, ${ }^{2}$ another concludes that available studies are inconclusive, ${ }^{3}$ and yet another suggests that the long term effects for cognition are probably negligible. ${ }^{4}$ However, these review studies agree that most previous studies are difficult to interpret, because of factors such as small sample size, lack of population based designs, and inadequate assessment and control for parental and socioeconomic factors. Another unresolved issue concerns the hypothesis that the neurodevelopment of infants born at biological risk, such as being SGA, may be particularly vulnerable to non-optimal parental and socioeconomic factors. ${ }^{5-8}$

The aims of the present study were, in relatively affluent Scandinavian societies: (1) to investigate whether term SGA children have lower mean preschool IQ compared to AGA control children, after controlling for potential confounding parental factors; (2) to estimate the relative importance of identifiable socioeconomic and parental factors and SGA in determining child IQ; (3) to test the hypothesis that the negative impact of low socioeconomic status on preschool cognitive development is greater for SGA compared to AGA children; and (4) to explore whether cognitive impairment in term SGA children may be related to specific prenatal risk factors for intrauterine growth retardation (IUGR) such as chronic maternal disease, low maternal prepregnancy weight, having a previous low birthweight or SGA child, or maternal smoking during pregnancy. Finally, we wanted to investigate whether additional risk was associated with symmetrical versus asymmetrical intrauterine growth retardation.

\section{Methods}

This study was part of a large prospective, cross national study on successive intrauterine growth retardation, the NICHD Study of Successive Small for Gestational Age Births (NSSSAB). The basic study design and details of the study population have been described previously. ${ }^{9}$ Between January 1986 and March 1988, parous mothers were recruited before 20 weeks of pregnancy from geographically defined regions at the three Scandinavian study sites, Trondheim and Bergen in Norway, and Uppsala in Sweden. Nulliparous women were not included because it was part of the intention of the study to examine the significance of repeated SGA births versus SGA births of mothers who had previously delivered AGA or large for gestational age infants. As it was necessary to complete questionnaires,
Correspondence to: Dr Sommerfelt email:ksom@haukeland.no

Accepted 21 March 2000 have been the major concern. Reviews inconclusive regarding the significance of SGA for subsequent IQ. One study suggests that 
women who did not speak a Scandinavian language were excluded.

Among the 6354 women referred to the study early during the second trimester, 5722 were eligible to participate. From this cohort a $10 \%$ sample $(\mathrm{n}=561)$ was randomly selected to form a reference group. This group and a group of women with identified risk factors for delivering an SGA infant were followed closely during pregnancy. The identified risk factors were: prepregnancy weight of less than $50 \mathrm{~kg}$, a previous perinatal death or birth of an SGA or low birthweight infant, relevant chronic maternal disease, and cigarette smoking at conception. ${ }^{9-11}$ Because of the high prevalence of smoking, only a $50 \%$ random sample of the women with smoking as the only risk factor was followed in detail during pregnancy. ${ }^{9}$ All infants in the $10 \%$ sample and all SGA infants, whether their mothers were followed closely during pregnancy or not, were the basis for the present study. The following subjects were excluded: preterm infants (born at less than 37 completed weeks of gestation), and infants with major malformations (two Down's syndrome and two meningomyelocele).

Results of follow up to 13 months of age have been published previously. ${ }^{12-14}$ Gestational age was based on last menstrual period (LMP) for approximately $72 \%$ of the infants and on ultrasound at 17-18 weeks of gestation for the others because of either uncertain LMP or a more than \pm 14 days discrepancy in estimate between ultrasound and LMP based gestational age. ${ }^{9}$ Children whose birthweights were below the 15 th centile for gestational age according to previously published reference standards from the Norwegian Birth Registry ${ }^{15}$ were defined as SGA, while those with higher birthweights were defined as AGA. The 15 th centile in a cohort where expected time of delivery is partially based on ultrasound measurements corresponds closely to the 10 th centile when dating is based on LMP, which was the basis for the national reference standard. ${ }^{9}{ }^{16}$ Consequently, the 15 th centile was considered most appropriate. The project protocol was approved by the regional ethics committee on medical research, and written consent was obtained from all parents.

Psychometric intelligence was assessed using a Norwegian version of the WPPSI-R IQ test. ${ }^{17}$ Full scale IQ (FIQ) combines performance IQ (PIQ) and verbal IQ (VIQ) scores. PIQ reflects non-verbal problem solving abilities, which include visuospatial and psychomotor processing abilities. VIQ reflects verbal abstraction, vocabulary, verbal reasoning, auditory perception, and arithmetic. As the WPPSI-R was not yet standardised in Norway or Sweden at the time of the study, the norms from the American version were used. Pure tone audiometry was used to diagnose hearing deficits, which could affect test results. The examiners were unaware of SGA/AGA status in all cases.

As it has been shown that socioeconomic and parental factors are very strong predictors of child cognitive development, probably both through hereditary and environmental effects, ${ }^{6718}$ a broad range of potential con- founding socioeconomic and parental factors were included. Information regarding parental smoking habits and parental education were obtained from questionnaires given to parents during pregnancy. Information regarding family economy was obtained from a questionnaire given to parents at the time of the five year examination. Maternal non-verbal problem solving abilities were assessed using the Raven Progressive Matrices. ${ }^{19}$ Maternal child rearing attitudes were assessed using a 65 item version of the Child Rearing Practices Report (CRPR). ${ }^{20-22}$ In this questionnaire a statement about an aspect of child rearing is given and the mother is asked to rate the items on a Likert scale from "strongly disagree" $=1$ to "strongly agree" $=6$. Dekovic et al reported that parental self reporting using the CRPR corresponded with actual parental behaviour with their child. ${ }^{23}$ As child rearing attitudes are highly culture dependent, it has been recommended that factor analyses are undertaken rather than depending on previously published scale constructs. ${ }^{20}$ Therefore, factor analysis including both study and control groups, was performed to reduce the number of variables. Principal components analysis, using Varimax rotation was utilised. ${ }^{24}$ This indicated that eigenvalues started to level off after three factors. As this number of factors yielded factors that could be interpreted meaningfully, a three factor model was chosen. From the contents of the items with high factor loadings on the different factors, the three factors were labeled "nurturance", "restrictiveness", and "loose limits". Nurturance and restrictiveness were very similar in factor loadings to similarly named factors identified by previous authors. ${ }^{23}{ }^{25}$ Inventory items with high loadings on the nurturance factor reflected a loving, supportive maternal attitude; those with high loadings on restrictiveness reflected such parental attitudes as expecting respect, protectiveness, restriction of showing feelings, and belief in physical punishment; and those with high loadings on the third factor, loose limits, reflected attitudes such as being reluctant with punishment, letting the child take chances and try things on its own, and not stopping rough games.

Maternal satisfaction with her social support network, including family, friends, and community support, was evaluated using the Inventory of Parents Experiences (IPE). ${ }^{26}$ The authors of the inventory supplied a version, which was slightly modified to apply to 5 year old children. Total score was used in the analysis because it has been shown to possess better psychometric properties than subscale scores. ${ }^{27}$ Maternal psychological distress, such as depression, anxiety, and psychosomatic symptoms, was assessed using a Norwegian translation of the Symptom Check List Revised (SCL-90-R). ${ }^{28}$ The total score (Global Stress Index) was used rather than subscale scores, as this has proved to be more reliable. ${ }^{28}$ The IPE and SCL-90-R were only administered at the two Norwegian sites, Bergen and Trondheim, and not in Uppsala. 
As previous research has indicated that PIQ has a stronger association with biological factors, and VIQ with environmental factors in this age group, PIQ and VIQ were analysed separately rather than using FIQ in the main analyses. $^{29}$

To facilitate interpretation of the analyses, the maternal Raven score, child rearing factor scores, maternal social support score, and maternal psychological distress score were $\mathrm{z}$ transformed to yield standardised variables with means of 0 and standard deviations of 1 .

STATISTICAL ANALYSIS

Firstly, mean group differences for the predictor and outcome variables were compared using $t$ tests, and differences in proportions using the $\chi^{2}$ test (table 2).

Secondly, the predictor variables presented in table 2 were made available to hierarchical stepwise multiple linear regression analyses with child PIQ as dependent variable. Cases with missing data on any of the variables included in the analysis, were excluded. In the stepwise procedure, we used standard criteria for entry and removal of variables with probability levels of $p=0.05$ for entry and $p=0.10$ for removal. To assess the crude relation between SGA/AGA status (entered as a 0-1 dummy variable: 0, AGA; 1, SGA) and child PIQ, this variable was entered in block 1 . Next, to assess the predictive significance of child SGA/AGA status while controlling for socioeconomic and demographic variables, maternal Raven score and monthly family income were made available to analysis in block 2 using a stepwise procedure for selection of variables. Maternal smoking during pregnancy was made available in block 3. Lastly, in block 4 , variables pertaining more specifically to the quality of the child rearing environment, namely child rearing style, were made available in a similar manner. Identical procedures were repeated with child VIQ as the dependent variable. Maternal social support and maternal psychological distress were not included in the main analyses as these questionnaires were not administered in the Swedish branch of the study. Separate analyses were repeated for PIQ and VIQ with these variables included in block 4 using only the Norwegian data.

Thirdly, we investigated the possibilities for interactions between the parental and family predictor variables that were statistically significant predictors of child PIQ in the multiple regression analyses by computing new variables which were the products of a parental variable and the SGA/AGA status variable. This computed variable, the parental variable, and the SGA/AGA status variable were forcibly entered into a multiple regression analysis with child PIQ or VIQ as dependent variables. Similar procedures were repeated using the other strong parental and family predictor variables.

Fourthly, we compared the mean IQ for SGA infants who had symmetrical growth retardation to those who had asymmetrical growth retardation. Asymmetrical growth retardation was defined as having a ponderal index $\left(\left(\right.\right.$ birth weight/birth length $\left.\left.{ }^{3}\right) \times 100\right)$ less than the 10th percentile for the same gender in the random reference sample. ${ }^{12}$

Confidence intervals are given wherever appropriate. An alpha level of 0.05 was adhered to throughout unless otherwise specified. Two tailed $\mathrm{p}$ values were employed throughout. SPSS for Windows was used for statistical analyses. ${ }^{24} 30$

\section{Results}

A total of 669 eligible SGA and AGA children were examined at 5 years of age. This constituted $67 \%$ of the total number of eligible children (table 1). Parents declining participation was the most common cause of loss to follow up (table 1). There were no significant differences within either the SGA or the AGA groups between children who were lost to follow up after birth and those who were assessed regarding gestational age or the available parental factors. More SGA (36\%) than AGA $(29 \%)$ children were lost to follow up $(p=0.01)$.

Mean FIQ was approximately four points lower for the SGA compared to the control children (table 2). The differences in mean FIQ between the SGA and AGA children at the three study sites were 99/104 in Bergen, $100 / 106$ in Trondheim, and 112/117 in Uppsala. The SGA and AGA families were comparable regarding maternal Raven score, maternal age, family income, child rearing practices, maternal social support, and maternal psychological distress (table 2). Maternal smoking during pregnancy was almost twice as common for the SGA compared to the AGA children (table 2). For many of these variables the data sets were incomplete, mainly because some parents declined to complete questionnaires (table 2). Data on parental education were incomplete as this questionnaire was accidentally not administered to mothers of SGA infants who were not in the $10 \%$ random reference sample or those followed closely because of recognised risk factors for SGA. Mean paternal education was 11.8 (SD 2.9)/12.8 (2.9) years $(\mathrm{p}=0.0001)$ and mean maternal education was $11.7(2.6) / 12.4 \quad(2.5)$ years $(\mathrm{p}=0.001)$ for the SGA and AGA families respectively. However, data on parental education were available for only 168 of the 338 SGA children who were tested and for 316 of the 335 AGA children. Parental education was therefore not included in the main analyses. Among the 335 tested AGA and 34 tested SGA children in the $10 \%$ random reference sample, parental education was available for 314 and 30 , respectively. For these, mean paternal education was $12.4(3.2) / 12.8$ (2.9) and mean maternal education was $12.4(2.8) / 12.4(2.5)$ for the SGA and AGA families respectively. None of these differences were statistically significant. In the $10 \%$ random sample mean paternal and maternal education were approximately 1.5 years shorter when the mothers smoked at conception $(n=111)$ compared to when they did not $(n=208, p<0.001$ for both). Among the SGA mothers, 58\% smoked at conception compared to $34 \%$ of the AGA mothers. 
Table 1 Number of children born in the project and causes of loss to follow up at 5 years of age

\begin{tabular}{lcccc}
\hline & Bergen & Trondheim & Uppsala & Total \\
\hline Children born & 228 & 237 & 595 & 1060 \\
Excluded because: & 12 & 13 & 36 & 61 \\
$\quad$ Prematurity & 2 & 0 & 0 & 2 \\
$\quad$ Down's syndrome & 0 & 1 & 1 & 2 \\
$\quad$ Meningomyelocele & 214 & 224 & 559 & 997 \\
$\quad$ Eligible children & 10 & 13 & 50 & 73 \\
Lost to follow up because: & 11 & 5 & 13 & 29 \\
$\quad$ Moved out of region & 4 & 15 & 196 & 215 \\
Untraceable & 25 & 33 & 262 & 320 \\
Declined & $189(88)$ & $191(85)$ & $297(53)$ & $677(68)$ \\
Total lost of eligible & & & & \\
Tested (\%) & & &
\end{tabular}

The difference in mean PIQ between the SGA and AGA children was reduced from 5.6 to 4.8 after controlling for confounding parental factors (table 3 ). The 5.6 points differ from the 4 points in the univariate analysis (table 2) because children with incomplete data for any of the independent variables were excluded in the multivariate analysis. For VIQ the difference in mean was 3.8 when only the SGA/AGA variable was included, and 4.2 in the full model (table 3). Maternal Raven score and the factor variables loose limits and nurturance were the strongest explanatory variables for both child PIQ and VIQ (table 3). One standard deviation of the $\mathrm{z}$ score for maternal Raven score corresponds to approximately 15 IQ points if maternal Raven score had been transformed to a standard IQ score. Using the unstandardised regression coefficient ( $\mathrm{B}$ in table 3 ) for maternal Raven score, this means that an increase in maternal IQ of 15 points corresponded to an increase in child PIQ of 3.6 points. For VIQ the comparable figure was 4.4 points. When the mother smoked at conception, mean child PIQ was 5.1 points lower than when she did not smoke when the other parental factors and SGA status were controlled for (table 3). Maternal smoking at conception was not a significant predictor of child VIQ when the other parental factors were controlled for (table 3).

When removing the SGA versus AGA variable from the last block of the PIQ regression analysis the explained variance was reduced by $2 \%$ (adjusted $\mathrm{R}^{2}$ reduced from 0.22 to 0.20 ), indicating that approximately $2 \%$ of the variance in child PIQ was attributable to birth weight and $20 \%$ to parental factors (table 3). Similarly, when removing the SGA versus AGA status variable the explained variance for VIQ was reduced by $1 \%$, leaving $30 \%$ explained by parental factors.

No statistically significant interaction effects were found between SGA status and the investigated parental predictor variables, including maternal smoking at conception, for either PIQ or VIQ.

Among the SGA children, there were no statistically significant associations between child IQ and low maternal prepregnancy weight (41/ 339), previous perinatal death (4/339), chronic maternal disease (5/339), or the mother having had a previous low birthweight child (74/339). SGA children with asymmetrical $(n=101)$ and symmetrical $(n=232)$ growth retardation did not differ significantly with respect to mean FIQ (mean FIQ 105 (15) versus 108 (16) respectively, $\mathrm{p}=0.07,95 \%$ confidence interval of difference in mean: -0.3 to 7.0 ).

\section{Discussion}

In the present study, mean IQ was slightly lower for the SGA compared to the AGA children. There was no indication that the parents of the SGA children differed significantly from those of AGA children regarding socioeconomic status, maternal IQ, maternal psychological wellbeing, or child rearing style, but the assessed parental factors dominated almost completely over SGA versus AGA status in predicting child IQ. There was no indication that the IQ of SGA infants was more affected than that of AGA children by negative effects of non-optimal parental factors including maternal smoking at conception. None of the assessed risk factors for intrauterine growth retardation were associated with lower IQ among the SGA children.

A weakness of the present study was loss to follow up. This loss was not evenly distributed across the study sites. However, differences in mean IQ between SGA and AGA children

Table 2 Child IQ and demographic data for the SGA and AGA families

\begin{tabular}{|c|c|c|c|c|c|c|}
\hline Birthweight group & $\begin{array}{l}\text { Mean } S G A \\
(S D)\end{array}$ & $\begin{array}{l}\text { Mean } A G A \\
(S D)\end{array}$ & $\begin{array}{l}\text { Difference } \\
\text { of means }\end{array}$ & $\begin{array}{l}95 \% \text { CI of } \\
\text { difference }\end{array}$ & $p(t$ test $)$ & $S G A / A G A(n)$ \\
\hline \multicolumn{7}{|l|}{ Child outcome } \\
\hline Full scale IQ & $106(15)$ & $110(15)$ & 4 & 2 to 6 & 0.0001 & $338 / 335$ \\
\hline Performance IQ & $108(15)$ & $112(14)$ & 4 & 2 to 7 & 0.0001 & $340 / 337$ \\
\hline Verbal IQ & $102(15)$ & $105(15)$ & 3 & 1 to 5 & 0.01 & $338 / 335$ \\
\hline \multicolumn{7}{|l|}{ Parental and family characteristics } \\
\hline Maternal Raven score ${ }^{\star} \dagger$ & $-0.03(1.1)$ & $0.03(0.92)$ & 0.06 & -0.1 to 0.23 & 0.47 & $274 / 259$ \\
\hline Maternal age (y) & $34.5(4.3)$ & $35.0(4.2)$ & 0.5 & -0.2 to 1.2 & 0.18 & $279 / 278$ \\
\hline Average monthly income (in $1000 \mathrm{NOK}$ ) & $25.5(9.9)$ & $26.8(10.5)$ & 1.3 & -0.4 to 3.0 & 0.12 & $290 / 291$ \\
\hline Child rearing practices: nurturance $\ddagger$ & $0.07(1.0)$ & $-0.07(1.0)$ & 0.15 & -0.3 to 0.01 & 0.06 & $336 / 330$ \\
\hline Child rearing practices: restrictiveness ${ }^{\star} \ddagger$ & $0.005(1.0)$ & $-0.005(1.0)$ & 0.01 & -0.14 to 0.16 & 0.90 & $336 / 330$ \\
\hline Child rearing practices: loose limits ${ }^{\star} \ddagger$ & $0.08(1.0)$ & $-0.08(1.0)$ & 0.15 & -0.3 to 0.001 & 0.06 & $336 / 330$ \\
\hline Maternal social support total score $\ddagger \int^{\top}$ & $-0.09(1.0)$ & $0.08(1.0)$ & 0.16 & -0.04 to 0.37 & 0.12 & $174 / 196$ \\
\hline \multirow[t]{2}{*}{ Maternal psychological distress $¥ \llbracket \mathbb{9}$} & $0.003(1.1)$ & $-0.003(0.9)$ & 0.006 & -0.21 to 0.2 & 0.95 & $171 / 198$ \\
\hline & Proportion & Proportion & & & $p\left(\chi^{2}\right)$ & \\
\hline Maternal smoking at conception (\%) & $145 / 252(58)$ & $114 / 337(34)$ & & & 0.00001 & \\
\hline
\end{tabular}

*These variables were used in the multivariate analyses (table 3 ).

†Raven progressive matrices test. The age corrected score was $z$ transformed to a mean of 0 and a standard deviation of 1

$\ddagger$ Scores were $\mathrm{z}$ transformed to a mean of 0 and a standard deviation of 1 .

§These questionnaires were only administered in the two Norwegian sites (Bergen and Trondheim) where 175 SGA and 205 AGA children were assessed.

qSCL-90-R General Stress Index. 
Table 3 Results of hierarchical stepwise multiple linear regression analyses in the combined $S G A(n=176)$ and AGA ( $n=228)$ groups that had complete data sets for the variables analysed

\begin{tabular}{|c|c|c|c|c|c|c|}
\hline Analysis block & Adjusted $R^{2}$ & Independent variables & $B$ & $95 \%$ CI of $B$ & beta & $p$ \\
\hline \multicolumn{7}{|l|}{ Dependent variable: child performance IQ (PIQ) } \\
\hline Block 1: SGA/AGA group & 0.03 & SGA/AGA group & -5.6 & -8.6 to -2.6 & -0.18 & 0.0001 \\
\hline Block 2: addition of socioeconomic variables & & Maternal Raven score & 5.2 & 3.8 to 6.7 & 0.33 & 0.0001 \\
\hline \multirow[t]{3}{*}{ and maternal Raven score } & 0.14 & SGA/AGA group & -5.1 & 7.9 to -2.3 & -0.16 & 0.0001 \\
\hline & & Maternal Raven score & 4.7 & 3.2 to 6.2 & 0.29 & 0.0001 \\
\hline & & Maternal smoking & -5.6 & -8.5 to -2.8 & -0.18 & 0.0001 \\
\hline \multirow[t]{5}{*}{ Block 3: addition of maternal smoking } & 0.16 & SGA/AGA group & -4.0 & -6.9 to -1.2 & -0.13 & 0.005 \\
\hline & & Maternal Raven score & 3.6 & 2.0 to 5.1 & 0.22 & 0.0001 \\
\hline & & Loose limits & -3.0 & -4.4 to -1.6 & -0.20 & 0.0001 \\
\hline & & Maternal smoking $\star$ & -5.1 & -7.9 to -2.3 & -0.16 & 0.0001 \\
\hline & & Nurturance & 2.5 & 1.2 to 3.8 & 0.16 & 0.0001 \\
\hline Block 4: addition of child rearing factors & 0.22 & SGA/AGA group & -4.8 & -7.5 to -2.0 & -0.15 & 0.001 \\
\hline \multicolumn{7}{|l|}{ Dependent variable: child verbal IQ (VIQ) } \\
\hline Block 1: birthweight group & 0.01 & SGA/AGA group & -3.8 & -6.9 to -0.9 & -0.13 & 0.01 \\
\hline Block 2: addition of socioeconomic variables & & Maternal Raven score & 6.3 & 4.9 to 7.6 & 0.41 & 0.0001 \\
\hline \multirow[t]{3}{*}{ and maternal Raven score } & 0.18 & SGA/AGA group & -3.2 & -5.8 to -0.5 & -0.11 & 0.02 \\
\hline & & Maternal Raven score & 5.9 & 4.5 to 7.3 & 0.38 & 0.0001 \\
\hline & & Maternal smoking ${ }^{\star}$ & -4.1 & -6.8 to -1.3 & -0.14 & 0.004 \\
\hline \multirow[t]{5}{*}{ Block 3: addition of maternal smoking } & 0.19 & SGA/AGA group & -2.4 & -5.1 to 0.2 & -0.08 & 0.07 \\
\hline & & Loose limits & 5.0 & 3.7 to 6.3 & 0.34 & 0.0001 \\
\hline & & Maternal Raven score & 4.4 & 3.0 to 5.7 & 0.29 & 0.0001 \\
\hline & & Nurturance & 2.6 & 1.4 to 3.8 & 0.18 & 0.0001 \\
\hline & & SGA/AGA group & -4.2 & -6.7 to -1.8 & -0.14 & 0.001 \\
\hline Block 4: addition of child rearing factors & 0.31 & Restrictiveness & 1.3 & 0.1 to 2.4 & 0.09 & 0.04 \\
\hline
\end{tabular}

SGA/AGA status, child gender, monthly family income, maternal Raven score, maternal smoking at conception, and the three child rearing practices factor variables (nurturance, restrictiveness, and loose limits) were made available to the analysis as independent variables. Maternal psychological distress and maternal social support were not included because these questionnaires were not administered in the Swedish sample. Parental education was not included in the analysis because of a large proportion of missing data. The independent variables in the table were those that made significant independent contributions to explaining variance in child IQ. B is the unstandardised regression coefficient.

were very similar across study sites, supporting an unbiased loss. The higher mean IQ in both SGA and AGA children in the Swedish site compared to both Norwegian sites, both using the same American norms, may be explained by Uppsala being a city with many inhabitants living there to receive higher education. Alternatively, the high loss to follow up in the Swedish site may have been skewed with more low socioeconomic status families not participating.

Another weakness was missing data, mainly concerning parental questionnaire data and maternal cognitive testing. However, such loss was generally evenly distributed among the SGA and AGA families, making it less likely that a significant parental confounding factor was missed.

Compared with the present study, somewhat greater differences of 5-10 points in IQ were reported for SGA and AGA children at preschool and school ages in two previous large population based studies. However, the children in these studies from New Zealand ${ }^{31} 32$ and Newcastle ${ }^{33}$ were born 14 and 26 years before the children in the present study. Improvements in obstetrical and neonatal management of IUGR in the intervening time period may to some extent have resulted in an SGA population with different causes and consequences of SGA and subsequently differences in the risk of neurodevelopmental problems. This could, for example, constitute a larger proportion of children with hereditary small body size in the present study and more children with compromised intrauterine fetal supply in the previous studies.

The several other studies addressing the relation between SGA birth and long term cognitive development are less reliable, mainly as a result of small sample size, lack of population based designs, and inadequate control groups. ${ }^{34-39}$ Other studies have the problem of including preterm children. ${ }^{40} 41$

While preterm births, whether SGA or AGA, have been consistently associated with low socioeconomic status and other parental risk factors,${ }^{67}$ SGA status for term births has been associated with low socioeconomic status in some, but not in other studies. ${ }^{33} 4243$ The findings of the present study suggest that SGA status in the Scandinavian countries is not significantly related to socioeconomic status. Consequently, it is unlikely that parental factors confounded the finding of lower mean IQ for the SGA children in the present study. Our results therefore indicate that IUGR is associated with a somewhat increased risk of non-optimal prenatal cerebral development. Causes for non-optimal development may be genetic or intrauterine environmental factors including infections, and circulatory and nutritional consequences of placental insufficiency. An alternative explanation to our finding, given the large impact of parental factors, is that unidentified parental factors confounded the results.

The very strong predictive power of even the simple parental factors assessed in the present study, and the very weak predictive power of SGA versus AGA status, supports previous interpretations that the attributable risk of adverse biological factors such as low birth weight or SGA status for cognitive developmental problems is very small. ${ }^{644}$ This finding, combined with the lack of statistically significant interactions between SGA status and parental or socioeconomic factors shown in the present and previous studies, ${ }^{67}$ undermines the widely held hypothesis ${ }^{58}$ that biological risk factors make infants particularly vulnerable to the negative effects of nonoptimal parental factors. The implication may be that strategies of intervention should target 
infants from families with definite parental risk factors and low socioeconomic status rather than the few infants with "low power" biological risk factors, such as SGA status or moderately low birth weight.

Maternal smoking during pregnancy is associated with being born $\mathrm{SGA},{ }^{45}$ as was also found in the present cohort. In the present study maternal smoking was associated with a reduction in mean child performance IQ of five points, similar to that associated with SGA status when parental factors were controlled for. This finding supports a negative biological effect of maternal smoking on fetal brain development, resulting in lower IQ, although we cannot rule out the possibility that the variable maternal smoking may exert its effect through confounding by non-optimal socioeconomic or child rearing parental factors. If real, the negative biological effect of maternal smoking during pregnancy was independent of whether the infant was SGA or AGA in the present study.

We conclude that SGA status is an independent risk factor for impaired cognitive development, but the effect is small and almost totally overshadowed by the effects of even crudely assessed parental factors, which are probably both of a hereditary and child rearing nature.

We thank all psychometricians and other participating personnel at the three study sites for the extensive work done to complete the data collection. This study was financed by NICHD NICHD research contract N01-HD-1-3127, the Norwegian Research Council (NFR) Grant No. 102697/320. Gunnar Ahland Linnea Carlssons Foundation.

1 Uvebrant P, Hagberg G. Intrauterine growth in children with cerebral palsy. Acta Paediatr 1992;81:407-12

2 Breart G, Poisson SAS. Intrauterine growth retardation and mental handicap: epidemiological evidence. Baillieres Clin Obstet Gynaecol 1988;2:91-100.

3 Grantham McGregor SM. Small for gestational age, term babies, in the first six years of life. Eur 7 Clin Nutr 1998;52 (suppl 1):59-64.

4 Hack M. Effects of intrauterine growth retardation on mental performance and behavior, outcomes during adolescence and adulthood. Eur f Clin Nutr 1998;52(suppl 1):S65-71.

5 Escalona SK. Babies at double hazard: early development of

6 infants at biologic and social risk. Pediatrics 1982;70:670-6. Hack M, Breslau N, Aram D, Weissman B, Klein N, Boraw-
ski CE. The effect of very low birth weight and social risk ski CE. The effect of very low birth weight and social risk
on neurocognitive abilities at school age. $\mathcal{F}$ Dev Behav Pedion neurocognitive abiti

7 Sommerfelt K, Ellertsen B, Markestad T. Parental factors in cognitive outcome of non-handicapped low birthweight infants. Arch Dis Child 1995; 73:F135-42.

8 Werner E, Simonian K, Bierman JM, French FE. Cumulative effect of perinatal complications and deprived environment on physical, intellectual, and social development of preschool children. Pediatrics 1967;39:490-505.

9 Bakketeig LS, Jacobsen G, Hoffman JH, Lindmark G, Bergsjø P, Molne K, Rødsten J. Pre-pregnancy risk factors of small-for-gestational age births among parous women in Scandinavia. Acta Obstet Gynecol Scand 1993;72:273-9.

10 Tenovuo A, Kero P, Piekkala P, Korvenranta H, Sillanpaa M, Erkkola R. Growth of 519 small for gestational age infants during the first two years of life. Acta Paediatr Scand 1987;76:636-46.

11 Ounsted M, Moar VA, Scott A. Children of deviant birthweight: the influence of genetic and other factors on

size at seven years. Acta Paediatr Scand 1985; 74:707-12.
12 Markestad T, Vik T, Ahlsten G, et al. Small-for-gestationalage (SGA) infants born at term: growth and development during the first year of life. Acta Obstet Gynecol Scand Suppl 1997;165:93-101

13 Vik T, Vatten L, Markestad T, Ahlsten G, Jacobsen G Bakketeig LS. Morbidity during the first year of life in smal for gestational age infants. Arch Dis Child Fetal Neonatal Ed 1996;75:F33-7.
14 Vik T, Markestad T, Ahlsten G, Gebre Medhin M, Jacobsen G, Hoffman HJ, Bakketeig LS. Body proportions and early neonatal morbidity in small-for-gestational-age infants of successive births. Acta Obstet Gynecol Scand Suppl 1997; $165: 76-81$.

15 Bjerkedal T, Skjaerven R. Percentiles of birth weight and crown-heel length in relation to gestation period for single live births. Tidsskr Nor Laegeforen 1980;100:1088-91

16 Bakketeig LS, Magnus P. Small for gestational age (SGA) definitions and associated risks. Int $\mathscr{F}$ Technol Assess Health Care 1992;8(suppl):139-46.

17 Wechsler D. WPPSI-R, Manual. The Psychological Corporation, 1989.

18 Bouchard TJ, McGue M. Familial studies of intelligence: a review. Science 1981;212:1055-9.

9 Raven JC. Progressive matrices. London: HK Lewis, 1965.

20 Block JH. The child-rearing practices report (CRPR): a set of O-items for the description of parental socialization, attitudes and values. Berkeley: University of California, Institute of Human Development, 1965.

21 Goldberg WA. Marital quality, parental personality, and spousal agreement about perceptions and expectations for

22 Greenberger E, Goldberg WA, Hamill S, O'Neil R, Et A. Contributions of a supportive work environment to parents' well being and orientation to work. Аm $\mathcal{F}$ Соттиnity Psychol 1989;17:755-83.

23 Dekovic M, Janssens JM, Gerris JR. Factor structure and construct validity of the Block Child Rearing Practices Report (CRPR). Psychological Assessment 1991;3:182-7.

24 SPSS for Windows. Advanced statistics, release 5. Chicago: SPSS Inc., 1992.

25 Rickel AU, Biasatti LL. Modification of the Block Child Rearing Practices Report. F Clin Psychol 1982;38:129-34.

26 Greenberg MT, Crnic KA. Longitudinal predictors of developmental status and social interaction in premature developmental status and social interaction in premature

27 Sexton D, Thompson B, Scott RL, Wood TA. Measurement characteristics of the Inventory of Parent Experiences Scales. Topics in Early Childhood Special Education 1990;10: $36-49$.

28 Derogatis LR. Administration, scoring and procedures manual-II. Clinical psychometric research. Maryland: Towser, 1983

29 Vohr B, Garcia CC, Flanagan P, Oh W. Effects of intraventricular hemorrhage and socioeconomic status on perceptual, cognitive, and neurologic status of low birth weigh infants at 5 years of age. 7 Pediatr 1992;121:280-5.

30 SPSS for Windows. Base system user's guide, release 6. Chicago: SPSS Inc., 1993.

31 Pryor JE. Physical and developmental status of preschool small for gestational age children: a comparative study. $\mathcal{F}$ Paediatr Child Health 1992;28:162-7.

32 Pryor J, Silva PA, Brooke M. Growth, development and behaviour in adolescents born small-for-gestational-age. $\mathcal{F}$ Paediatr Child Health 1995;31:403-7.

33 Neligan GA, Kolvin I, Scott DM, Garside RF Pres. Born too soon or born too small: a followup study to seven years of age. London: William Heinemann Medical Books, Spastics International Medical Publications, 1976.

34 Ounsted MK, Moar VA, Scott A. Children of deviant birthweight at the age of seven years: health, handicap, size and developmental status. Early Hum Dev 1984;9:323-40.

35 Villar J, Smeriglio V, Martorell R, Brown CH, Klein RE. Heterogeneous growth and mental development of intrauterine growth retarded infants during the first 3 years of life. Pediatrics 1984;74:783-91.

36 Harvey D, Prince J, Bunton J, Parkinson C, Campbell S. Abilities of children who were small for gestational age babies. Pediatrics 1982;69:296-300.

37 Lagerstrom M, Bremme K, Eneroth P, Faxelius G, Magnusson D, Smedler A. WISC test scores at the age of 10 for son $\mathrm{D}$, Smedler A. WISC test scores at the age of 10 for
children born to women with risk pregnancies. $\mathcal{F}$ Perinat Med 1991;19:269-83.

38 Winer EK, Tejani NA, Atluru V, DiGiuseppe R, Borofsky LG. Four to seven year evaluation in two groups of small for gestational age infants. Am f Obstet Gynecol 1982;143: $425-9$.

39 Drew JH, Bayly J, Beischer NA. Prospective follow up of growth retarded infants and of those from pregnancies complicated by low oestriol excretion. Aust $N Z \mathcal{F}$ Obstet Gynaecol 1983;23:150-4.

40 Rantakallio P. A 14 year follow up of children with normal and abnormal birth weight for their gestational age. A population study. Acta Paediatr Scand 1985;74:62-9.

41 Nilsen ST, Finne PH, Bergsjo P, Stamnes O. Males with low birthweight examined at 18 years of age. Acta Paediatr Scand $1984 ; 73: 168-75$.

42 Fikree FF, Berendes HW. Risk factors for term intrauterine growth retardation: a community-based study in Karachi. growth retardation: a community-based

43 Silva PA, McGee R, Williams S. A longitudinal study of the intelligence and behavior of preterm and small for gestational age children. F Dev Behav Pediatr 1984;5:1-5.

44 Naeye RL, Peters EC. Antenatal hypoxia and low IQ values. Am $\mathcal{F}$ Dis Child 1987;141:50-4.

5 Kramer MS. Determinants of low birth weight: methodological assessement and meta-analysis. Bull World Health Organ 1987;65:663-737. 